\title{
Low Sucrose and High Gibberellic Acid Levels Positively Regulates Relative Growth Rate and Organogenesis in D. Membranaceus Munro
}

\author{
Jasmine Brar*1, Manju Anand ${ }^{1}$ and Anil Sood ${ }^{2}$
}

${ }^{1}$ Department of Biotechnology, Thapar University, Patiala, Punjab, India

${ }^{2}$ Division of Biotechnology, CSIR-Institute of Himalayan Bioresource Technology, Palampur, HP, India.

\section{Commentary}

Dendrocalamus membranaceus Munro., an economically important edible bamboo has been listed as a priority species requiring conservation by International Union for Conservation of Nature (IUCN) and hence selected for the present investigations. It is opined that the cells of bamboo are undoubtedly totipotent but some vital hormonal and/or nutritional factor or their combination could prove vital for differentiation as the frequency of embryogenesis is lower than that of organogenesis [1]. The role of organic compounds like sucrose and growth regulators like Gibberellic acid $\left(\mathrm{GA}_{3}\right)$ effects the relative growth rate (RGR) of callus in-turn effecting overall organogenesis and ultimately leading towards somatic embryogenesis. Carbohydrates are transported within the plants mainly in the form of sucrose and the level of sugar within the medium needs to be optimum for proper organogenesis [2]. $\mathrm{GA}_{3}$ was used for enhanced growth and to promote cell elongation during shoot bud differentiation in $D$. hamiltonii $[3,4]$. Takeno et al., [5] demonstrated that the relatively high levels of endogenous GA-like substances were required at early stages of embryogenesis followed by a rapid decrease of free GAs. Till date the roles of auxins and cytokinins in organogenesis/embryogenesis were investigated very well, however, we do not have a complete understanding of the involvement of $\mathrm{GA}_{3}$ in organogenesis as its effects vary in different tissues and species and needs further more investigations.

\section{Role of Sucrose}

Researchers have claimed that the addition of high concentration of sucrose in the culture media might have inhibitory effect on nutrient uptake by lowering water potential of the medium [6]. Growth rate studies were carried out using various concentrations of sucrose ranging from 1 to $5 \%$ as shown in Figure 1a-e and Table 1. Sucrose (1\%) with a RGR of $0.46 \pm 0.0 \mathrm{mg} / \mathrm{g} /$ day with a corresponding increase in Growth Index (5.62 \pm 0.50$)$ and Cell Increase Ratio (4.62 \pm 0.50$)$ was observed. RGR kept on decreasing as the concentration of sucrose was increased to $5 \%$ keeping rest of the medium composition similar. Thus a definite correlation between sucrose concentration and RGR was established confirming the role of sucrose as the main carbon source for providing energy and increasing the biomass. It has also been indicated that sucrose concentration influences the overall growth of callus, browning and its proliferation [7]. In Dendrocalamus asper, Arya et al., [8] found $2 \%$ sucrose to be best for callus growth while higher sucrose (6\%) concentration retarded the callus growth and its multiplication. Similarly, in B. edulis, Lin et al., [9] used 3-6\% sucrose and found that $3 \%$ sucrose gave the best response for embryogenic callus proliferation. In contrast, Yeh and Chang [10] found 6\% sucrose to be beneficial for callus proliferation in B. beecheyana. In D. membranaceus, best results regarding callus proliferation were obtained using $1 \%$ sucrose as also reported by Rao et al., [11] in D. strictus.

\section{Gibberellic acid (GA $)$}

As the application of $\mathrm{GA}_{3}$ was found to have an effect on the growth rate in many bamboo species, experiments were conducted using varying concentrations of $\mathrm{GA}_{3}(1.1$ to $2.8 \mu \mathrm{M})$ in the media (Figures $2 \mathrm{a}-2 \mathrm{c}$ ) alongwith $4.53 \mu \mathrm{M}$ of 2,4-D. RGR was found to be maximum i.e. $0.63 \pm 0.05 \mathrm{mg} / \mathrm{g} /$ day when $2.8 \mu \mathrm{M}$ of $\mathrm{GA}_{3}$ was used (Table 2) with a GI of $7.37 \pm 0.50$ and a CIR of $6.37 \pm 0.50$. Our results were in consonance with Gautam et al., [12] where also high concentrations of $\mathrm{GA}_{3}(>5$ $\mu \mathrm{M} ; 1-8 \mathrm{mg} / \mathrm{l}$ ) positively regulated the growth of undifferentiated callus cells in Matthiola incana.

This is the first report in D. membranaceus citing that the optimum concentration of organic supplements and $\mathrm{GA}_{3}$ enhances the rates of

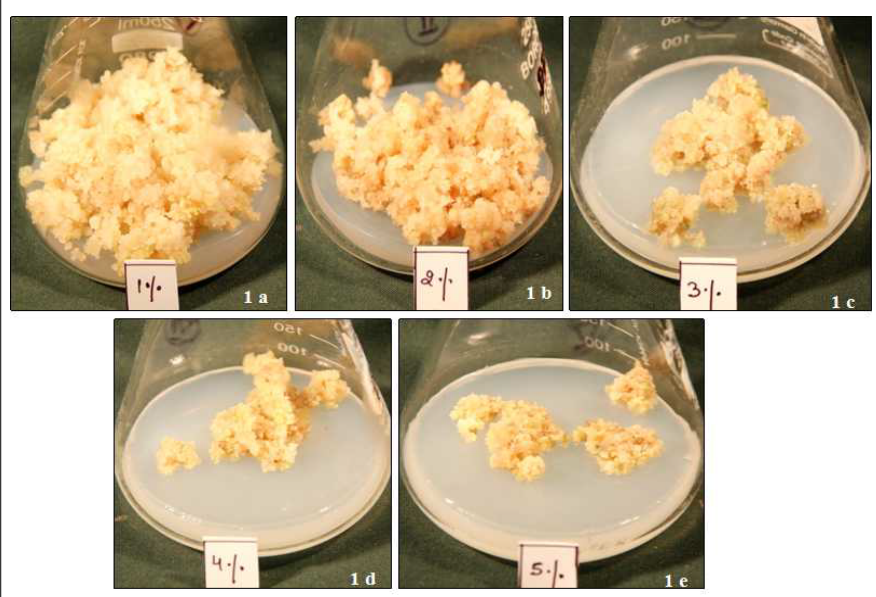

Figures 1: Relative growth of callus on different concentrations of sucrose showing highest.

\begin{tabular}{|c|l|l|l|l|}
\hline Sucrose $\%$ & $\mathbf{R G R} \mathbf{~ m g / g / d a y}$ & $\mathbf{G I}$ & $\mathbf{C I R}$ & Colour of Callus \\
\hline 1 & $0.46^{\mathrm{a}} \pm 0.05$ & $5.62^{\mathrm{a}} \pm 0.50$ & $4.62^{\mathrm{a}} \pm 0.50$ & Creamish \\
\hline 2 & $0.32^{\mathrm{b}} \pm 0.02$ & $4.25^{\mathrm{b}} \pm 0.24$ & $3.25^{\mathrm{b}} \pm 0.24$ & Creamish+light brown \\
\hline 3 & $0.24^{\mathrm{c}} \pm 0.02$ & $3.40^{\mathrm{c}} \pm 0.23$ & $2.40^{\mathrm{c}} \pm 0.23$ & Creamish+light brown \\
\hline 4 & $0.16^{\mathrm{d}} \pm 0.02$ & $2.66^{\mathrm{d}} \pm 0.23$ & $1.66^{\mathrm{d}} \pm 0.23$ & Creamish \\
\hline 5 & $0.11^{\mathrm{e}} \pm 0.01$ & $2.11^{\mathrm{e}} \pm 0.16$ & $1.11^{\mathrm{e}} \pm 0.16$ & Creamish \\
\hline
\end{tabular}

Mean of 5 replicates. Different uppercase letters within the columns indicate significant difference among treatments (Duncan's multiple range test, $P \leq 0.05$ )

Table 1: Effect of sucrose concentrations on relative growth rate (RGR).

*Corresponding author: Jasmine Brar, Department of Biotechnology, Thapar University, Patiala, Punjab-147004; India; E-mail: jasminethapar83@gmail.com Received: June 24, 2015; Accepted: July 07, 2015; Published July 09, 2015

Citation: Brar J, Anand M, Sood A(2015) Low Sucrose and High Gibberellic Acid Levels Positively Regulates Relative Growth Rate and Organogenesis in D. Membranaceus Munro. Biochem Anal Biochem 4: 198. doi:10.4172/2161-1009.1000198

Copyright: (c) 2015 Brar J, et al. This is an open-access article distributed under the terms of the Creative Commons Attribution License, which permits unrestricted use, distribution, and reproduction in any medium, provided the original author and source are credited. 